Original article

\title{
Prevalence and risk factors of female sexual dysfunction among women infected with HIV in conakry
}

\author{
Alioune Camara ${ }^{\mathrm{a}, \mathrm{b}, *}$, Thierno Mamadou Tounkara ${ }^{\mathrm{b}, \mathrm{c}}$, Alexandre Delamou ${ }^{\mathrm{a}, \mathrm{b}}$, \\ Raghiatou Baldé $^{\mathrm{a}}$, Niouma Nestor Leno ${ }^{\mathrm{a}, \mathrm{d}}$, Gerard Christian Kuotu ${ }^{\mathrm{a}}$, Abdoulaye Touré ${ }^{\mathrm{a}}$, \\ Mohamed Cissé ${ }^{c}$ \\ ${ }^{a}$ Department of Public Health, Faculty of Health Sciences and Techniques, Gamal Abdel Nasser University Conakry, Guinea \\ ${ }^{\mathrm{b}}$ African Center of Excellence for Prevention and Control of Communicable Diseases (CEA-PCMT), Faculty of Health Sciences and Techniques, Gamal Abdel Nasser \\ University, Conakry, Guinea \\ ${ }^{\mathrm{c}}$ Department of Dermatology and Sexually Transmitted Infections, Gamal Abdel Nasser University of Conakry Faculty of Health Sciences and Techniques, Conakry, \\ Guinea \\ ${ }^{\mathrm{d}}$ National Program for Health Care and Prevention of STIs / HIV / AIDS of the Ministry of Health, Conakry, Guinea
}

\section{A R T I C L E I N F O}

\section{Keywords:}

Prevalence

Risk factors

Female sexual dysfunction

HIV/AIDS

Guinea

\begin{abstract}
A B S T R A C T
Background: Female sexual dysfunction is a highly prevalent sexual health problem but under-investigated in Guinea. This study determined the prevalence and risk factors associated with sexual dysfunction among women infected with human immunodeficiency virus (HIV) in Conakry.

Methods: The Female Sexual Function Index (FSFI) was used in a cross-sectional study design involving 401 women aged 18 years or more in large HIV cohort sites in Conakry, Guinea. A score of less than 26.55 indicated sexual dysfunction. Clinical and sociodemographic characteristics were collected. Multivariate logistic regression analysis was performed to identify factors associated with sexual dysfunction.

Results: The prevalence of sexual dysfunction was $22.2 \%$ (95\% CI: 18.2-25.9). The types of sexual dysfunctional detected included desire disorder (32.2\%), sexual arousal (25.4\%), lubrication (23.9\%), orgasm (30.7\%), sexual satisfaction (32.7\%) and pain (28.2\%). Multivariate analysis showed that unmarried (adjusted OR 4.6, 95\% CI 1.6 to 14.0 ), age above 35 years old (adjusted OR 7.2, 95\% CI 2.1 to 24.0), voluntary HIV screening (OR 4.69: $95 \%$ CI: 1.07, 21.93), and current use of antiretroviral drugs (OR 2.68: 95\% CI: 1.28, 5.61) were factors associated with sexual dysfunction.

Conclusion: Sexual dysfunction is prevalent in women infected with HIV in Conakry, Guinea. Sociodemographic and clinical factors were associated with the risk of sexual dysfunction. Health care workers should be trained on the screening and management of sexual dysfunction in HIV care services.
\end{abstract}

\section{Introduction}

Adequate sexual functioning is an essential part of being human, especially for women. ${ }^{1,2}$ Female sexual dysfunction (FSD) is a complex phenomenon including desire, arousal, orgasmic and sexual pain disorders. ${ }^{3}$ It affects the lives of many women worldwide. ${ }^{4,5}$ Among women, sexual disorders are characterized by subjective reports of difficulties or limitations in the sexual domains affected. ${ }^{6}$ Women with chronic diseases such as human immunodeficiency virus (HIV) have been reported to experience sexual dysfunction related to sexual desire, arousal, orgasm, and dyspareunia. ${ }^{7}$ Among the tools for screening for
FSD, the Female Sexual Function Index (FSFI) is widely used and has criteria for each area of dysfunction. ${ }^{8}$

The global burden of HIV infection is currently over 38 million in 2019, with Sub-Saharan Africa being disproportionately affected. ${ }^{9}$ Women and girls accounted for 58\% of the 240,000 [150,000-390,000] new infections estimated in 2019 in the West and Central Africa region. ${ }^{10}$

Little is known about sexual dysfunction in the context of HIV infection in resource-limited settings. ${ }^{6}$

It has been noted that women living with HIV/AIDS with sexual dysfunction display impaired psychological wellbeing and non-

\footnotetext{
* Corresponding author. Department of Public Health, Faculty Of Health Sciences And Techniques, Gamal Abdel Nasser University Conakry, Guinea.

E-mail address: aliounec@gmail.com (A. Camara).
} 
adherence to antiretroviral therapy. ${ }^{11,12}$ Yet, there are many reasons to expect an increase in sexual dysfunction in HIV-positive individuals. ${ }^{3}$ In many settings, especially in Sub-Saharan Africa (SSA), people living with HIV are not expected to have a sex life because of the risk of transmission of the virus. ${ }^{13}$ Fewer studies have evaluated sexual functioning in women living with HIV/AIDS. ${ }^{6}$ With an HIV prevalence estimated at $1.5 \%$ of people aged $15-55$ years, Guinea also lacks data on this topic. ${ }^{14}$ In addition, there are currently no guidelines to manage sexual dysfunction in the HIV care setting in the country.

To promote sexual well-being among women living with HIV, data on sexual function are needed to identify and appropriately care for victims. Therefore, it has become increasingly important to identify the frequency and risk factors associated with sexual dysfunction among women infected with HIV. ${ }^{11}$

The objective of this study was to determine the prevalence and risk factors of sexual dysfunction among women infected with HIV in Conakry, Guinea.

\section{Methods}

\subsection{Study setting}

Conakry, the capital of Guinea has the highest HIV prevalence rate in the country: $2.7 \%$. With a population of 1.77 million, the city is by far the most populous and urbanized in the country. Conakry comprises five communes: Kaloum, Dixinn, Matam, Matoto and Ratoma. This study was conducted at 11 large cohort HIV treatment sites. The distribution of women interviewed by site is shown in Fig. 1. In these sites, the preferred first-line ART regimen was a combination of tenofovir (TDF), lamivudine (3 TC) and efavirenz (EFV).

\subsection{Study design}

This was a cross-sectional study conducted at the primary, intermediate and tertiary care clinics. HIV-positive patients attending treatment centers were invited to participate in the study between August 2020 and January 2021.

\subsection{Study population}

We included women aged 18 years or more who had known their HIV status for 6 months or more who consented to participate and answer the questionnaire. We excluded HIV patients unable to answer the questionnaire, such as hearing, speaking or mental impairment and those not consenting properly. Participation was voluntary after informed consent, and confidentiality was maintained across the study.

\subsection{Sampling procedures}

Convenience sampling was used to select the sites, which is a nonrandom sampling method. This type of sampling is suitable to select women presenting at large cohort HIV treatment sites. The minimal sample size for this study was calculated using EPI INFO version 7, with a $95 \% \mathrm{CI}, 5 \%$ margin of error and assuming a prevalence of sexual dysfunction to be $53.3 \% .{ }^{15}$ Assuming a $10 \%$ non-response rate, a total sample size of $382 \mathrm{HIV}$ women was required. In total, 420 respondents distributed proportionaly to the size of the HIV treatment cohorts were recruited for this study.

\subsection{Data and measures}

Data were collected by interviewer using a standardized

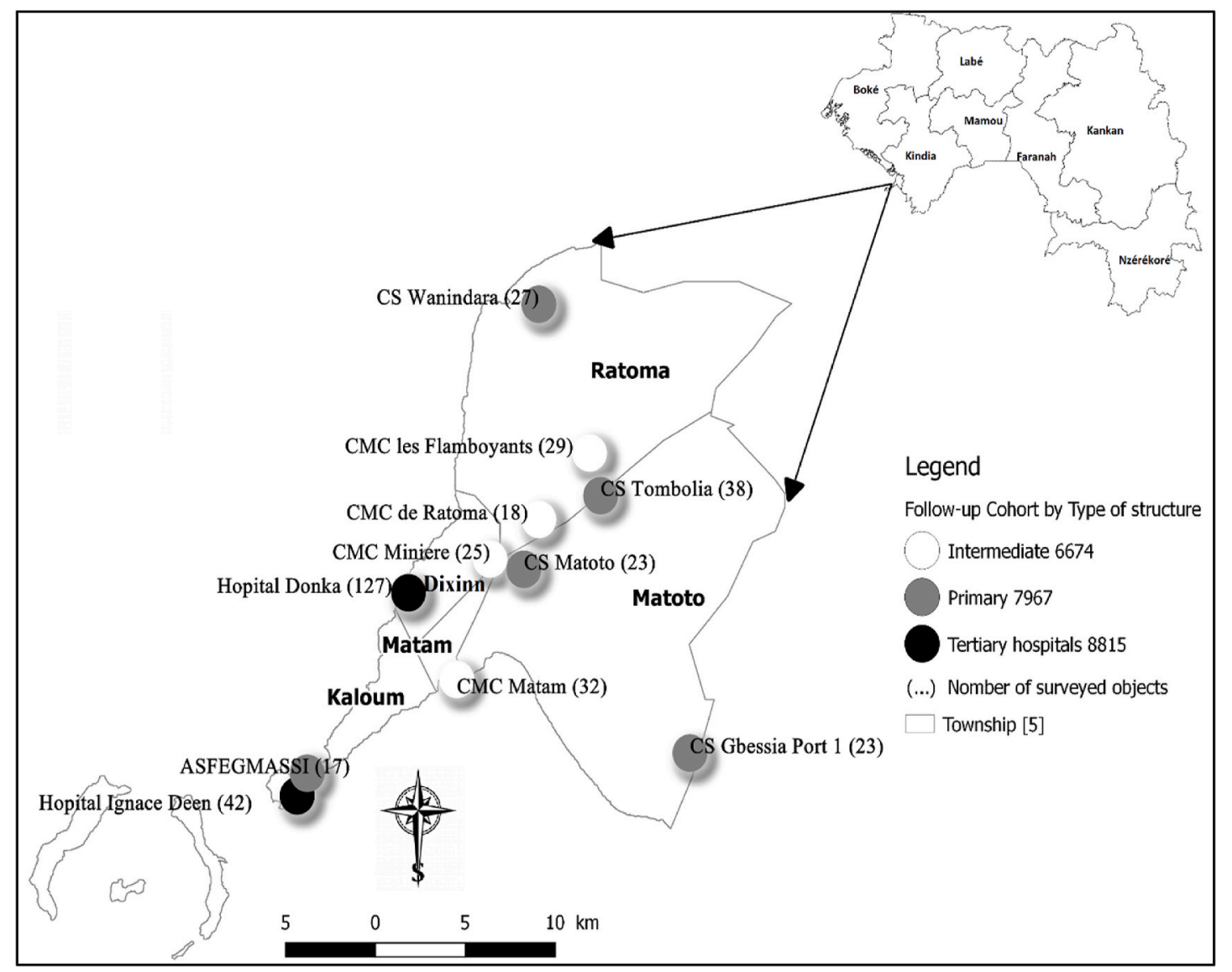

Fig. 1. Location map of the 11 large cohort sites for surveys in the 5 townships of Conakry, Guinea. 
questionnaire. For this study, the questionnaire included three components: (i) sociodemographic background such as age, type of structure (Tertiary, Intermediate, Primary), education (Unable to read and write, Primary or more), residence (Conakry, Urban, Rural), marital status (Married, Unmarried); (ii) medical characteristics such as circumstance of HIV diagnosis (Coincidental, Voluntary screening, Biological exploration), diagnosis announcement (After counselling, Without counselling), current HIV treatment (Yes, No), time since HIV diagnosis, body mass index, medical history (Yes if Diabetes and/or hypertension and/or Hepatitis, No), Current opportunistic infection (Yes, No); and (iii) the Female Sexual Function Index (FSFI), used to evaluate sexual functioning during the last four weeks. ${ }^{8}$ The French version of the FSFI was used for most women. It was translated in Susu language for participants who could not speak or understand French. ${ }^{16}$ The FSFI consists of 19 questions covering six domains - desire (2 questions), arousal (4), lubrication (4), orgasm, satisfaction, and pain (3 questions each). Responses to each question relating to the previous month were scored from 0 (no sexual activity) to 5 (normal sexual activity). Individual domain scores are obtained by adding the scores of the individual questions of the domain and total score was obtained by adding up domains. The cut off score used was 26.55 , as suggested by the authors of FSFI. ${ }^{8}$ This cut off is reliable in identifying the presence or absence of various sexual function disorders. ${ }^{2,8,17,18}$ Cut off values for different domains are as follows: Desire $(<4.28)$, Arousal $(<5.08)$, Lubrication $(<5.45)$, Orgasm $(<5.05)$, Satisfaction $(<5.04)$, Pain $(<5.51) .{ }^{19}$

\subsection{Data analysis}

Means, frequencies, proportions, and rates of the given data for each variable were calculated.

The internal consistency was assessed by calculating Cronbach's alpha values for all domains and each domain separately. Bivariate analysis was performed to characterize the association of each independent variable with sexual dysfunction. Variables having a p-value less than 0.2 were entered into the multivariate logistic regression model using a stepwise approach to identify the effect of each independent variable on sexual dysfunction. All statistical analyses were performed using SPSS version 26 (SPSS, Chicago, IL, USA). For all tests, $\mathrm{p}<0.05$ was deemed statistically significant and $95 \%$ confidence intervals were calculated. Before starting the study, validity and reliability were tested in a pilot study, using 20 HIV-positive patients in an unselected site in Conakry. The Cronbach's alpha was found to be 0.8 in French version and 0.7 in the Sousou version, which is within the acceptable limits for reliability.

\subsection{Ethical consideration}

The study protocol was approved by the scientific committee of the chair of public health of the University of Conakry, under $\mathrm{N}^{\circ} 048 / \mathrm{CSP} /$ FSTS/UGANC/2020 dated 17 July 2020. The questionnaire was administered by medical personnel in the Cares Clinics who informed the women about the research and its objectives. Participants were assured that would will be maintained during and after the study. Information given was used only for the purpose of this study. Women infected with HIV with sexual dysfunction were referred for further investigations and care if necessary.

\section{Results}

\subsection{Sociodemographic and clinical characteristics}

Among 420 eligible women invited to the survey, 401 consented (representing a participation rate of $95.5 \%$ ). There were no differences in proportion of sex, mean age and time since HIV diagnosis between respondents and non-respondents (data not shown).

Table 1 shows the characteristics of the participants in our study. The
Table 1

Sociodemographic characteristics of 401 women infected with HIV included in survey of female sexual dysfunction, Conakry, Guinea.

\begin{tabular}{llll}
\hline Characteristic & & \multicolumn{2}{l}{ Frequency (\%) } \\
\hline Type of structure & Tertiary & 165 & $(41.1)$ \\
& Intermediate & 105 & $(26.2)$ \\
& Primary & 131 & $(32.7)$ \\
Education & Unable to read and write & 214 & $(53.4)$ \\
& Primary and plus & 187 & $(46.6)$ \\
Residence & Conakry & 317 & $(79.1)$ \\
& Urban & 63 & $(15.7)$ \\
\multirow{2}{*}{ Marital status } & Rural & 21 & $(5.2)$ \\
& Married & 175 & $(43.6)$ \\
Age category (years) & Unmarried & 226 & $(56.4)$ \\
& $<35$ years & 204 & $(50.9)$ \\
Age, Mean (SD) & $\geq 35$ years & 197 & $(49.1)$ \\
& & 35.0 & $( \pm 8.6)$ \\
\hline
\end{tabular}

mean age $( \pm \mathrm{SD})$ of the sample was $35.0 \pm 8.6$ years, ranging from 18 years to 62 years. The majority of the respondents were living in Conakry $(79.1 \%)$, received care in a tertiary structure $(41.1 \%)$, were unable to read and write (53.4\%) and were unmarried (56.4\%).

Nearly all participants had diagnosis announcement after counselling (96.8\%), type 1 of HIV (98.8\%) and where currently using antiretroviral treatment (80.3\%). The mean time duration from HIV diagnosis to study enrolment was $5.3( \pm 3.8)$ years. Among all study participants, $31(7.7 \%)$ had a current opportunistic infection (Table 2$)$.

\subsection{Prevalence of sexual dysfunction among HIV patients during the last four weeks}

The reliability analysis of the FSFI showed excellent consistency (Cronbach's $\alpha=0.98$ ). The mean scores for the FSFI domains were desire (5.7 \pm 2.2$)$, arousal $(10.5 \pm 6.4)$, orgasm $(8.3 \pm 5.1)$, satisfaction $(8.0 \pm 5.2)$, and pain $(8.9 \pm 5.5)$. The mean total FSFI score was $52.2 \pm$ 29.2 .

Table 3 shows that of the 401 female patients interviewed, 89 (22.2\%; CI 18.2-25.9) had sexual dysfunction. Types of sexual dysfunction included disorder of desire $(32.2 \%)$, arousal $(25.4 \%)$, lubrication $(23.9 \%)$, orgasm $(30.7 \%)$, satisfaction $(32.7 \%)$ and pain (28.2\%). Overall, the median sexual functioning score over the last four weeks in the sample was 59 (range 2-94) (Table 4).

Table 2

Medical characteristics of 401 women infected with HIV included in survey of female sexual dysfunction, Conakry, Guinea.

\begin{tabular}{|c|c|c|c|}
\hline \multicolumn{2}{|l|}{ Characteristics } & \multicolumn{2}{|c|}{ Frequency (\%) } \\
\hline \multirow[t]{3}{*}{ Circumstance of diagnosis } & Coincidental & 42 & $(10.5)$ \\
\hline & Voluntary screening & 121 & $(30.2)$ \\
\hline & Biological exploration & 238 & $(59.4)$ \\
\hline \multirow[t]{2}{*}{ Diagnosis announcement } & After counselling & 388 & $(96.8)$ \\
\hline & Without counselling & 13 & $(3.2)$ \\
\hline \multirow[t]{2}{*}{ Type of HIV } & Type 1 & 396 & $(98.8)$ \\
\hline & Type $1+2$ & 5 & $(1.2)$ \\
\hline \multirow[t]{2}{*}{ Treatment with ARV } & Yes & 322 & $(80.3)$ \\
\hline & No & 79 & (19.7) \\
\hline \multirow[t]{2}{*}{ Body Mass Index category } & $\leq 25 \mathrm{~kg} / \mathrm{m}^{2}$ & 314 & (78.3) \\
\hline & $>25 \mathrm{~kg} / \mathrm{m}^{2}$ & 87 & $(21.7)$ \\
\hline \multicolumn{2}{|l|}{ Body Mass Index, Mean $( \pm S D)$} & \multicolumn{2}{|c|}{$23.0( \pm 2.9)$} \\
\hline \multirow[t]{2}{*}{ Comorbidities $^{\mathrm{a}}$} & Yes & 61 & $(15.2)$ \\
\hline & No & 340 & $(84.8)$ \\
\hline \multirow[t]{2}{*}{ Current opportunistic infection ${ }^{\mathrm{b}}$} & Yes & 31 & $(7.7)$ \\
\hline & No & 370 & $(92.3)$ \\
\hline
\end{tabular}

a Diabetes mellitus $(\mathrm{n}=21)$; hypertension $(\mathrm{n}=37)$; Hepatitis $(\mathrm{n}=19)$.

b Tuberculosis $(n=12)$; Shingles $(n=10)$; Diarrhea $(n=5)$; Kaposi $(n=2)$; Candidiasis $(\mathrm{n}=2)$. 
Table 3

Overall and domain-specific Female Sexual dysfunction prevalence during last 4 weeks in 401 women infected with HIV included in survey of female sexual dysfunction, Conakry, Guinea.

\begin{tabular}{llll}
\hline Sexual dysfunction & Frequency & $(\%)$ & $95 \%$ CI \\
\hline All domains & 89 & $(22.2)$ & $18.2-25.9$ \\
Desire domain & 129 & $(32.2)$ & $27.7-36.9$ \\
Arousal domain & 102 & $(25.4)$ & $21.0-29.7$ \\
Lubrication domain & 96 & $(23.9)$ & $19.7-28.2$ \\
Orgasm domain & 123 & $(30.7)$ & $26.2-35.2$ \\
Satisfaction domain & 131 & $(32.7)$ & $27.9-37.4$ \\
Pain domain & 113 & $(28.2)$ & $23.9-32.7$ \\
\hline
\end{tabular}

Table 4

Mean standard deviation and score range for six domains of FSFI among 401 women infected with HIV included in survey of female sexual dysfunction, Conakry, Guinea.

\begin{tabular}{llllll}
\hline Score & Mean & \pm SD & Median & Minimum & Maximum \\
\hline Desire domain & 5.7 & 2.2 & 6 & 2 & 10 \\
Arousal domain & 10.5 & 6.4 & 12 & 0 & 20 \\
Lubrication domain & 10.9 & 6.6 & 13 & 0 & 20 \\
Orgasm domain & 8.3 & 5.1 & 10 & 0 & 15 \\
Satisfaction domain & 8.0 & 5.2 & 9 & 0 & 15 \\
Pain domain & 8.9 & 5.5 & 10 & 0 & 15 \\
All domains & 52.2 & 29.2 & 59 & 2 & 94 \\
\hline
\end{tabular}

\subsection{Factors associated with sexual dysfunction among HIV patients} during the last four weeks

Table 5 shows the relationship between each of the risk factors and HIV patients at risk of developing sexual dysfunction.

In the multivariate analysis, we found that unmarried women were 3.92 times more likely to have sexual dysfunction than those married (95\% CI: 2.14, 7.16). Women aged above 35 years old were 5.27 times at increased risk of sexual dysfunction than women under 35 years (95\% CI: $2.96,9.40$ ). Similarly, women who discovered their status through voluntary screening (OR 4.69: 95\% CI: 1.07, 21.93), and who were currently using antiretroviral drugs (OR 2.68: 95\% CI: 1.28, 5.61), were more likely to have sexual dysfunction.

No association was found between type of structure, education, residence, body mass index category, type of HIV, diagnosis announcement, annual monitoring, current opportunistic infection, medical history, and sexual dysfunction.

\section{Discussion}

There is a critical need and value for more African studies to examine the real burden of sexual dysfunction in women living with HIV. This study found a prevalence of $22.2 \%$ of sexual dysfunction among women living with HIV in Conakry. The prevalence of sexual dysfunction in our study was comparable with of the proportion of $25.8 \%$ reported among women without HIV from Malaysia ${ }^{20}$ and $25 \%$ among HIV-positive women from Europe. ${ }^{3}$ A systematic review reported a prevalence of sexual dysfunction ranging from $32 \%$ to $61 \%$ among females living with HIV. ${ }^{21}$ On the other hand, our findings are lower than the three studies conducted in Nigeria where the reported prevalences were $95 \%$ among women of reproductive, ${ }^{22} 89.2 \%$ among women living with $\mathrm{HIV}^{6}$ and $53.3 \%$ among female students respectively. ${ }^{23}$ The proportion found in our study is also lower than the $88 \%$ reported among diabetic women in Nigeria ${ }^{5}$ and the $79.2 \%$ found among Chinese women with type 2 diabetes. ${ }^{24}$ In some reports, sexual dysfunction was common among women suffering from chronic diseases. ${ }^{3,25}$ It is unclear whether sexual problems result from the illness, its treatment, or psychogenic factors. The exact mechanisms or pathogenesis of sexual dysfunction among HIV infected individuals is not well understood. Beckman suggested that hormonal, vascular, psychological, neurological factors or cellular function disorders may be involved just like in HIV-un-infected individuals. $^{26}$

Only a few studies have determined the prevalence of the subtypes of female sexual dysfunction in Africa. ${ }^{6}$ In the present study, the lowest means score was observed for the desire domain, followed by the satisfaction and pain domains. In Nigeria, the lowest score was observed for the arousal domain, followed by the pain and lubrication domains. ${ }^{6}$ In the same study, by using the same cut-off value of all domains, the prevalence of desire disorder (87.8\%), arousal (75.1\%), lubrication $(60.8 \%)$, orgasm $(62.2 \%)$, satisfaction $(45.9 \%)$ and pain $(62.4 \%)$ was much less than our study findings. ${ }^{6}$ Different definition thresholds of the FSFI make it difficult to compare studies with each other. ${ }^{2,3}$ In these studies, regarding the individual domains, a score of less than $65 \%$ of the maximum achievable score was considered to indicate dysfunction in that domain. Thus, a score of less than 3.9 in each domain was considered to indicate sexual dysfunction. ${ }^{2,3,6}$ Also, the understanding and meaning of the various sexual health concepts might vary across cultures and languages.

The present study found that being unmarried, age above 35 years, voluntary screening, and antiretroviral therapy are associated with sexual dysfunction. Increasing age as a risk factor for sexual dysfunction was also found in other studies. ${ }^{20,27}$ It is possible that the hormonal changes associated with aging in women may account for the increasing loss of sexual functioning with age. ${ }^{28}$ Women going through hormonal changes in their body show an impact on their sexual functioning. Hormonal changes associated with menopause and aging, such as oestrogen/androgen depletion, often cause important physical and psychological adverse effects on sexual function. ${ }^{29}$

The present study found that the use of antiretroviral drugs is associated with sexual dysfunction. These findings are consistent with findings from other studies. ${ }^{3}$ Sexual dysfunction has been previously associated with the use of antiretroviral drugs, especially protease inhibitors. ${ }^{30}$ Attributing an influence of antiretroviral drugs on sexual dysfunction may however, be difficult when combinations of drugs are used and when most individuals have had sequential exposure to antiretroviral drugs. ${ }^{3}$ Schrooten reports in a study that, androgen deficiency was considered to be the main cause of SD in advanced HIV infection. ${ }^{30}$ The present study showed there was an association between being unmarried and female sexual dysfunction. Also in Nigeria, being currently married remained significantly associated with increasing FSFI scores. ${ }^{2}$

Our findings underline physicians and caregivers' need for sensitisation to assess sexual disorders during routine consultations in HIV programs.

\subsection{Limitations}

The cross-sectional study design did not assess the temporal relationship between sexual dysfunction and factors. Our study recruited women with HIV from Conakry, and hence, we cannot generalize to the entire HIV patient population in Guinea. Also, the FSFI has been criticized for assuming that penetration is required for sexual well-being. ${ }^{12}$ Furthermore, only sociodemographic and medicals characteristics factors were used for assessment in this study. The study would have been more robust if data on factors such as socioeconomic status, sexual partner, female genital mutilation, parity, anxiety, and depression were collected. Despite these limitations, this study provides baseline data for exploring the sexuality and well-being in the context of HIV-positive women in large cohort sites.

\section{Conclusion}

Sexual dysfunction is a significant problem among women living with HIV in Conakry, Guinea. There is a need to sensitize and train physicians and caregivers to assess for sexual problems during routine consultations in HIV programs. The national HIV program in Guinea 
Table 5

Factors associated with Sexual dysfunction among 401 women infected with HIV included in survey of female sexual dysfunction, Conakry, Guinea.

\begin{tabular}{|c|c|c|c|c|c|c|c|c|c|c|}
\hline & \multicolumn{4}{|c|}{ Sexual dysfunction } & \multirow[b]{2}{*}{ OR } & \multirow[b]{2}{*}{$95 \% \mathrm{CI}$} & \multirow[b]{2}{*}{$\mathrm{p}$} & \multirow[b]{2}{*}{ AOR } & \multirow[b]{2}{*}{$95 \% \mathrm{CI}$} & \multirow[b]{2}{*}{$\mathrm{p}$} \\
\hline & No, $n$ & $(\%)$ & Yes, $\mathrm{n}$ & $(\%)$ & & & & & & \\
\hline Type of structure & & & & & & & 0.37 & & & \\
\hline Tertiary & 129 & $(78.2)$ & 36 & $(21.8)$ & 1.18 & $0.67-2.09$ & 0.56 & & & \\
\hline Intermediate & 77 & $(73.3)$ & 28 & $(26.7)$ & 1.54 & $0.83-2.85$ & 0.17 & & & \\
\hline Primary & 106 & $(80.9)$ & 25 & $(19.1)$ & 1 & - & & & & \\
\hline Education & & & & & & & 0.02 & & & \\
\hline Unable to read and write & 157 & $(73.4)$ & 57 & $(26.6)$ & 1.75 & $1.08-2.86$ & & & & \\
\hline Primary and plus & 155 & $(82.9)$ & 32 & $(17.1)$ & 1 & - & & & & \\
\hline Residence & & & & & & & 0.16 & & & \\
\hline Conakry & 246 & $(77.6)$ & 71 & $(22.4)$ & 5.77 & $0.76-43.8$ & 0.90 & & & \\
\hline Urban & 46 & $(73.0)$ & 17 & $(27.0)$ & 7.39 & $0.92-59.4$ & 0.60 & & & \\
\hline Rural & 20 & $(95.2)$ & 1 & $(4.8)$ & 1 & - & & & & \\
\hline Marital status & & & & & & & $<0.001$ & & & ${ }^{<} 0.001$ \\
\hline Married & 157 & $(89.7)$ & 18 & $(10.3)$ & 1 & - & & 1 & - & \\
\hline Unmarried & 155 & $(68.6)$ & 71 & $(31.4)$ & 3.99 & $2.28-7.01$ & & 3.92 & $2.14-7.16$ & \\
\hline Age category & & & & & & & $<0.001$ & & & ${ }^{<} 0.001$ \\
\hline$<35$ years & 184 & $(90.2)$ & 20 & $(9.8)$ & 1 & - & & 1 & - & \\
\hline$\geq 35$ years & 128 & $(65.0)$ & 69 & $(35.0)$ & 4.95 & $2.87-8.56$ & & 5.27 & $2.96-9.40$ & \\
\hline Body Mass Index category & & & & & & & 0.27 & & & \\
\hline$\leq 23 \mathrm{~kg} / \mathrm{m}^{2}$ & 178 & $(79.8)$ & 45 & $(20.2)$ & 1 & - & & & & \\
\hline$>23 \mathrm{~kg} / \mathrm{m}^{2}$ & 134 & (75.3) & 44 & $(24.7)$ & 1.3 & $0.81-2.08$ & & & & \\
\hline Type of HIV & & & & & & & 0.90 & & & \\
\hline Type 1 & 308 & $(77.8)$ & 88 & $(22.2)$ & 1.14 & $0.12-10.35$ & & & & \\
\hline Type $1+2$ & 4 & $(80.0)$ & 1 & $(20.0)$ & 1 & - & & & & \\
\hline Circumstance of diagnosis & & & & & & & 0.03 & & & 0.05 \\
\hline Coincidental & 40 & $(95.2)$ & 2 & $(4.8)$ & 1 & - & & 1 & - & \\
\hline Voluntary screening & 88 & $(72.7)$ & 33 & $(27.3)$ & 7.5 & $1.71-32.79$ & 0.08 & 4.69 & $1.07-21.93$ & 0.05 \\
\hline Biological exploration & 184 & $(77.3)$ & 54 & $(22.7)$ & 5.87 & $1.37-25.07$ & 0.02 & 2.73 & $0.60-12.48$ & 0.19 \\
\hline Diagnosis announcement & & & & & & & 0.93 & & & \\
\hline After consuling & 302 & $(77.8)$ & 86 & $(22.2)$ & 1 & - & & & & \\
\hline Without consuling & 10 & $(76.9)$ & 3 & $(23.1)$ & 1.05 & $0.28-3.91$ & & & & \\
\hline Treatment with ARV & & & & & & & 0.52 & & & 0.01 \\
\hline Yes & 244 & $(75.8)$ & 78 & $(24.2)$ & 1.97 & $0.99-3.92$ & & 2.68 & $1.28-5.61$ & \\
\hline No & 68 & $(86.1)$ & 11 & (13.9) & 1 & - & & 1 & - & \\
\hline Annual monitoring & & & & & & & 0.20 & & & \\
\hline$<4$ times/year & 91 & $(82.0)$ & 20 & $(18.0)$ & 1 & - & & & & \\
\hline$\geq 4$ times/year & 219 & $(76.0)$ & 69 & $(24.0)$ & 1.43 & $0.82-2.49$ & & & & \\
\hline Current opportunistic infection & & & & & & & 0.09 & & & \\
\hline Yes & 28 & $(90.3)$ & 3 & $(9.7)$ & 1 & - & & & & \\
\hline No & 284 & $(76.8)$ & 86 & $(23.2)$ & 2.82 & $0.83-9.52$ & & & & \\
\hline Medical history & & & & & & & 0.01 & & & \\
\hline Yes & 40 & $(65.6)$ & 21 & $(34.4)$ & 2.10 & $1.16-3.79$ & & & & \\
\hline No & 272 & $(80.0)$ & 68 & $(20.0)$ & 1 & - & & & & \\
\hline
\end{tabular}

should include guidelines for the screening and treatment of sexual dysfunctions in HIV-positive patients in national recommendations for the management of HIV infection.

\section{Financial support}

This research received no specific grant from any funding agency, commercial or not-for-profit sectors.

\section{Authors' contributions}

Alioune Camara: Conceptualization, Methodology. All authors approved the study protocol. Raghiatou Baldé, Gerard Christian Kuotu and Niouma Nestor Leno collected data. Alioune Camara, Thierno Mamadou Tounkara, and Alexandre Delamou performed the analysis and wrote the manuscript. Abdoulaye Touré: Software, Validation. Mohamed Cissé: Supervision, Reviewing and Editing. All authors commented on the manuscript project, then read and approved the final manuscript.

\section{Data sharing statement}

Further information on the data supporting the findings of this study can be obtained from aliounec@gmail.com.

\section{Declaration of competing interest}

The authors declare that they have no competing interests.

\section{Acknowledgements}

The authors appreciate the respective study institutions and the study participants for their cooperation in providing the necessary information. We also acknowledge the assistance of Mateusz M. Plucinski (Centers for Disease Control and Prevention, Atlanta, Georgia, USA) in the preparation of this manuscript.

\section{References}

1 Pizzarossa LB, Perehudoff K. Global survey of national constitutions. Health Hum Rights. 2017;19:279-293.

2 Abiodun O, Sodeinde K, Adepoju A, et al. Sexual functioning, sexual distress, and well-being of sexually active adult women living with HIV: an HIV program-based cross-sectional study. Sex Res Soc Pol. 2020;17:558-567.

3 Florence E, Schrooten W, Dreezen C, et al. Prevalence and factors associated with sexual dysfunction among HIV-positive women in Europe. AIDS Care. 2004;16: $550-557$.

4 Carreiro AV, Micelli LP, Sousa MH, Bahamondes L, Fernandes A. Sexual dysfunction risk and quality of life among women with a history of sexual abuse. Int J Gynaecol Obstet Off Organ Int Fed Gynaecol Obstet. 2016;134:260-263.

5 Ogbera AO, Chinenye S, Akinlade A, Eregie A, Awobusuyi J. Frequency and correlates of sexual dysfunction in women with diabetes mellitus. J Sex Med. 2009;6: 3401-3406. 
6 Agaba PA, Meloni ST, Sule HM, Agaba EI, Idoko JA, Kanki PJ. Sexual dysfunction and its determinants among women infected with HIV. Int J Gynecol Obstet. 2017; 137:301-308.

7 Aerts L, Enzlin P, Verhaeghe J, Poppe W, Vergote I, Amant F. Long-term sexual functioning in women after surgical treatment of cervical cancer stages IA to IB: a prospective controlled study. Int J Gynecol Cancer Off J Int Gynecol Cancer Soc. 2014 24:1527-1534.

8 Rosen R, Brown C, Heiman J, et al. The Female Sexual Function Index (FSFI): a multidimensional self-report instrument for the assessment of female sexual function. J Sex Marital Ther. 2000;26:191-208.

9 Organisation Mondiale de la Santé. Principaux repères sur le VIH/sida. https://www. who.int/fr/news-room/fact-sheets/detail/hiv-aids; 2021. Accessed February 10, 2021.

10 Unaids. Global AIDS Update - seizing the moment — tackling entrenched inequalities to end epidemics. https://www.unaids.org/en/resources/documents/20 20/global-aids-report; 2020, 2020, February 10, 2021.

11 Trotta MP, Ammassari A, Murri R, d'Arminio Monforte A, Antinori A. Sexual dysfunction in HIV infection. Lancet. 2007;369:905-906.

12 Pinzone MR, Gussio M, Bellissimo F, et al. Self-reported sexual dysfunction in HIVpositive subjects: a cross-sectional study. Infect Dis Trop Med. 2015;1:E104-E109.

13 Shapiro K, Ray S. Sexual health for people living with HIV. Reprod Health Matters. 2007;15:67-92.

14 Institut National de la Statistique Ministère du Plan et du Développement Economique Conakry. Guinée. Enquête Démographique et de Santé. https://www. unicef.org/guinea/rapports/enqu\%C3\%AAte-d\%C3\%A9mographique-et-de-sant\% C3\%A9-2018; 2018. Accessed February 10, 2021.

15 Horo K, Yéo-Ténéna J-MY, Koffi MO, et al. Anxiété et dépression au cours du traitement antirétroviral à Abidjan. Inf Psychiatr. 2014;90:373-379.

16 Wylomanski S, Bouquin R, Philippe H-J, et al. Psychometric properties of the French female sexual function index (FSFI). Qual Life Res. 2014;23:2079-2087.

17 Wiegel M, Meston C, Rosen R. The female sexual function index (FSFI): crossvalidation and development of clinical cutoff scores. J Sex Marital Ther. 2005;31: $1-20$.

18 Anis TH, Gheit SA, Saied HS, Al kherbash SA. Arabic translation of female sexual function index and validation in an Egyptian population. J Sex Med. 2011;8: $3370-3378$.
19 Ezeani I, Onyeonoro U, Ugwu E. Evaluation of female sexual function in persons with type 2 diabetes mellitus seen in a tertiary hospital in southeast Nigeria with emphasis on its frequency and predictors. J Sex Marital Ther. 2020;46:170-176.

20 Ishak IH, Low W-Y, Othman S. Prevalence, risk factors, and predictors of female sexual dysfunction in a primary care setting: a survey finding. J Sex Med. 2010;7: 3080-3087.

21 Huntingdon B, Muscat DM, de Wit J, Duracinsky M, Juraskova I. Factors associated with general sexual functioning and sexual satisfaction among people living with HIV: a systematic review. J Sex Res. 2020;57:824-835.

22 Shittu RO, Alabi KM, Odeigah LO, Sule AG, Ampitan A, Odeigah CC. Female sexual dysfunction in women of reproductive age group in Nigeria, West Africa. Niger J Fam Pract. 2017;8.

23 Nwagha UI, Oguanuo TC, Ekwuazi K, et al. Prevalence of sexual dysfunction among females in a university community in Enugu, Nigeria. Niger J Clin Pract. 2014;17: 791-796.

24 Shi YF, Shao XY, Lou QQ, Chen YJ, Zhou HJ, Zou JY. Study on female sexual dysfunction in type 2 diabetic Chinese women. Biomed Environ Sci BES. 2012;25: $557-561$.

25 Rahmanian E, Salari N, Mohammadi M, Jalali R. Evaluation of sexual dysfunction and female sexual dysfunction indicators in women with type 2 diabetes: a systematic review and meta-analysis. Diabetol Metab Syndrome. 2019;11:73.

26 Beckman TJ, Abu-Lebdeh HS, Mynderse LA. Evaluation and medical management of erectile dysfunction. Mayo Clin Proc. 2006;81:385-390.

27 Oyedokun A, Odeigah LO, Alabi KM, Adegunloye OA, Akujobi HC. Sexua dysfunction in HIV-positive women attending a tertiary health facility in North Central Nigeria. J AIDS Clin Res. 2014;5:2.

28 Bernhard LA. Sexuality and sexual health care for women. Clin Obstet Gynecol. 2002; 45:1089-1098.

29 Dawson ML, Shah NM, Rinko RC, Veselis C, Whitmore KE. The evaluation and management of female sexual dysfunction. J Fam Pract. 2017;66:722-728.

30 Schrooten W, Colebunders R, Youle M, et al. Sexual dysfunction associated with protease inhibitor containing highly active antiretroviral treatment. AIDS Lond Engl. 2001;15:1019-1023. 